\title{
Construção de uma tecnologia assistiva para validação entre cegos: enfoQue na amamentação*
}

\author{
Creation of an assistive technology for validation among blind people: focus on breastfeeding
}

Construcción de una tecnología asistiva para validación entre ciegos: enfoque en la lactancia

\section{Paula Marciana Pinheiro Oliveira', Cristiana Brasil de Almeida Rebouças', Lorita Marlena Freitag Pagliuca'}

'Universidade Federal do Ceará. Curso de Pós-Graduação. Fortaleza, CE

\section{RESUMO}

Objetivou-se construir tecnologia assistiva na temática amamentação para validação por cegos. Esta tecnologia é um cordel Que será cantarolado por repentistas para, posteriormente, ser apreciado por cegos. Realizou-se no período de maio a junho de 2008 e consta de 32 sextilhas, distribuídas nas categorias: 1 . Composição do leite materno; 2. Mitos e tabus; 3. Profissional, família e amamentação; 4 . Vantagens da amamentação para a criança; 5 . Vantagens da amamentação para a mãe e família; 6 . Comunicação em saúde. A partir deste cordel, ressaltase a importância do enfermeiro atuar na promoção da saúde e prevenção de doenças além de utilizá-lo como meio de comunicação e incentivo ao aleitamento.

Descritores: Literatura; Promoção em saúde; Aleitamento Materno; Tecnologia.

\section{ABSTRACT}

This study aimed to construct an assistive technology about breastfeeding for validation among blind people. This technology is a string that will be sung by street musicians, and then evaluated by blind people. It was performed in May and June 2008 and comprises 32 units of six lines, distributed in categories: 1. Composition of mother's milk; 2. Myths and taboos; 3. Professional, family and breastfeeding; 4. Advantages of breastfeeding for the child; 5 . Advantages of breastfeeding for the mother and family; 6 . Communication in health. By elaborating the string the importance of nurses in health promotion and disease prevention and it can use the string as a means for communication and encouragement of breastfeeding is highlighted.

Descriptors: Literature; Health Promotion; Breast Feeding; Technology.

\section{RESUMEN}

El objetivo fue construir una tecnología asistiva con la temática lactancia para validación entre ciegos. Esta tecnología es un cordel Que será canturreado por repentistas, para, posteriormente, ser apreciado por ciegos. Fue realizado durante el período de mayo a junio de 2008 y incluye 32 sextillas, distribuidas en las categorías: I. Composición de la leche materna; 2. Mitos y tabús; 3 . Profesional, familia y lactancia; 4. Ventajas de la lactancia para el niño; 5 . Ventajas de la lactancia para la madre y familia; 6 . Comunicación en salud. Con el cordel, se resalta la importancia del enfermero en la promoción de la salud y prevención de enfermedades, además utilizar el cordel como medio de comunicación e incentivo a la lactancia.

Descriptores: Literatura; Promoción de la Salud; Lactancia Materna; Tecnología. 


\section{INTRODUÇÃO}

A tecnologia pode ser considerada como um processo constituído por um conjunto de ações abstratas e concretas e Que tem finalidades. Esta tecnologia permeia todo processo de trabalho em saúde. A partir da idéia principal, a implementação é ferramenta essencial para o cuidado em saúde, além de ser ressaltada nas relações entre os agentes ${ }^{(1)}$.

De acordo com a classificação, as tecnologias podem ser divididas em leve, leve-dura e dura, respectivamente. A leve, Quando trata de relações, acolhimento; a leve-dura, Quando se refere aos saberes bem estruturados, como o processo de enfermagem; e dura, Quando envolve os equipamentos tecnológicos do tipo máeuinas e também as normas ${ }^{(2)}$.

Nesta perspectiva, ao enfatizar a tecnologia no contexto da saúde, o enfermeiro, como profissional adequado para a educação em saúde, é responsável pela criação de diversas estratégias no seu ambiente de trabalho como forma de dinamizar a assistência. Para alguns, porém, determinadas estratégias utilizadas podem não ser a melhor maneira de assimilar um aprendizado. Por exemplo, as pessoas com deficiência, especificamente o deficiente visual, não conhecem o instrumento dependente da visão como eficaz na difusão do conhecimento em saúde.

No caso dos cegos ou de pessoas com visão subnormal, a comunicação ocorre basicamente pelo tato e audição. Por isso, os materiais preparados para estas pessoas devem possuir características específicas ${ }^{(3)}$. Entre as tecnologias possíveis ao uso desta clientela, encontra-se a tecnologia assistiva, conhecida como todos os serviços e recursos responsáveis por ampliar as habilidades funcionais e a autonomia de pessoas com deficiência ${ }^{(4)}$.

$\mathrm{Na}$ literatura de cordel, são encontradas histórias escritas, de modo geral, retratando a vida de cangaceiros baseadas em disputas, além de assuntos diversos. Abordam temas na área da saúde, tais como: diabetes, aids, dengue, mulher, amamentação, entre outros. O cordel é um instrumento Que pode ser explorado como forma de disseminar conhecimentos em decorrência da sua estrutura fundamentada na rima, além de poder ser cantarolado por profissionais repentistas e pela população em geral. Desse modo, o cordel pode ser incluído no meio educativo.

Dia-a-dia a literatura de cordel tem se tornado expressivo meio de alfabetização e incentivo à leitura junto às populações carentes do Nordeste ${ }^{(5)}$. Ademais, como instrumento usado para se aprender a ler, deve contribuir para o conhecimento destas pessoas, ou seja, ser informativo o suficiente para transmitir as informações. Ao mesmo tempo, deve possibilitar a assimilação deste conteúdo e provocar discussões com os colegas e familiares ${ }^{(6)}$.

Como se percebe, é crescente o interesse de educadores e estudantes de todo o Brasil pela literatura de cordel, sobretudo em escolas públicas da Região Nordeste. Este veículo de comunicação de massas, batizado como "professor folheto", foi responsável durante muito tempo pela alfabetização de milhares de nordestinos na primeira metade do século $X X^{(5)}$.

$\mathrm{Na}$ área da saúde, estudos referentes à temática HIV/Aids e amamentação já foram realizados utilizando este meio de comunicação $^{(6,7)}$. Em tais estudos encontrou-se Que o cordel é um meio eficaz e eficiente de educação em saúde. Esta eficácia, no entanto, deve se estender à clientela cega, pois o acesso desta população à educação em saúde ainda é limitado.

A exemplo de várias temáticas na saúde abordadas nos cordéis, como HIV/Aids, diabetes, álcool e drogas, entre outros, a amamentação é de grande relevância por propiciar a aproximação mãe e filho. Ademais, é benéfica para ambos, pois protege o bebê contra infecções e alergias e favorece seu crescimento e desenvolvimento adequado. Além de fortalecer o vínculo entre a mãe e o bebê, a amamentação diminui o risco de obesidade e diabetes e também traz benefícios importantes para a saúde materna, particularmente os relacionados à diminuição da incidência de câncer de mama e de ovário, entre outros ${ }^{(8)}$.

Nesta perspectiva, objetivou-se construir uma tecnologia assistiva com a temática amamentação para validação entre cegos.

\section{METODOLOGIA}

Trata-se de um estudo de desenvolvimento de tecnologia assistiva em saúde para incentivo à amamentação. Estudos deste tipo têm o intuito de contribuir para a vida mais autônoma de pessoas com deficiência e, ao mesmo tempo, promover a inclusão destas pessoas. Isto por desenvolver recursos e serviços Que contribuem para tal ${ }^{(3)}$. Nesta perspectiva, o recurso desenvolvido foi um material educativo sobre aleitamento materno Que terá como sujeitos a população de cegos para apreciar o material.

Esta tecnologia construída é um cordel a ser cantarolado por repentistas para, posteriormente, ser apreciado por pessoas com deficiência visual. O interesse pela construção deste material partiu da experiência com trabalho anterior no Qual foi feita uma análise de mensagens transmitidas e da linguagem adotada em um cordel sobre a temática amamentação ${ }^{(6)}$.

Neste material analisado, percebeu-se sua importância como instrumento de educação em saúde, porém foram constatados alguns equívocos relacionados à literatura científica. Com isso, houve empenho, como enfermeira, para a elaboração de um cordel. Um cordelista foi consultado para revisão da tecnologia.

Com o referencial teórico já estudado, adotado como embasamento teórico para a construção da tecnologia, concretizou-se a idéia de elaboração do material. O trabalho desenvolveu-se durante o período de maio a junho de 2008 , e é parte, também, de um projeto de dissertação, cuja amostra será constituída de pessoas com deficiência visual para apreciação, como referido.

Mencionado cordel consta de 32 sextilhas, estrofes com seis versos, dispostos da seguinte maneira: o segundo, Quarto e sexto versos têm rimas e o primeiro, terceiro e Quinto versos são livres. Usa-se rima, isto é, a correspondência de sons, escritos com palavras diferentes. A métrica é a utilização da medida de sílabas, estas contadas até a última sílaba tônica, resultando em heptassílabos, enQuanto a oração é a coerência, a coordenação e a precisão, dando fidelidade e objetividade ao tema.

Quanto à classificação dos versos, as estrofes têm os seguintes tipos: verso agudo, o Qual termina em palavra oxítona ou em monossílabo tônico; verso grave, Que termina em palavra paroxítona; e verso esdrúxulo, finalizando em palavra proparoxítona. Nestes versos também foram usadas a elisão, ou seja, a fusão de duas ou mais vogais no mesmo verso, formando apenas uma sílaba ${ }^{(5)}$.

Como referido, o cordel será apresentado em categorias, discutidas à luz dos referenciais teóricos pertinentes ao tema. 


\section{RESULTADOS E DISCUSSÃO}

Os resultados serão apresentados de acordo com a construção da tecnologia, nas seguintes categorias: 1. Composição do leite materno; 2. Mitos e tabus; 3. Profissional, família e amamentação; 4. Vantagens da amamentação para a criança; 5 . Vantagens da amamentação para a mãe e família; 6 . Comunicação em saúde.

\section{Categoria I. Composição do leite materno}

\section{É com a amamentação \\ Que nós vamos conhecer \\ As vantagens para a mãe \\ Vamos nós esclarecer \\ E também para o bebê \\ Veja bem isso é normal}

As cores são diferentes

Bem do início pro final

O primeiro mais aguado

Isto é muito natural

Coloração transparente

Veja bem isso é normal

Tem este leite materno

Na própria composição

Vitaminas, anticorpos

Estes para a proteção

Também tem gorduras, água

Tudo pra alimentação

No fim de cada mamada

Mais gordura o leite tem

Por isso Que esta cor muda

Amarelado detém

E assim é Que vai engordando

Esta criança também

Ele possui várias cores

É necessário lembrar

A alimentação materna

Todos vamos concordar

$O$ alimento Que a mãe ingere

É Que faz essa cor dar

É no leite materno Que se encontram não apenas os nutrientes necessários para o crescimento e desenvolvimento do recémnascido, mas também anticorpos Que proporcionam visível proteção contra as infecções (I). $^{2}$.

Muitas mulheres se impressionam com a cor do leite. Esta pode variar de acordo com a dieta da mãe, e também conforme a duração da mamada de cada criança. Um leite mais amarelado decorre de uma dieta mais rica de betacaroteno, assim como terá predominantemente essa cor Quando está no fim da mamada ${ }^{(10)}$.

Quanto à constituição do leite materno e segundo mostra a literatura, possui água suficiente para saciar a sede da criança. Portanto, dispensa o uso de água e de chá. Ademais, contém gordura e proteína adeQuadamente, vitaminas A, B, D, E, tiamina, riboflavina, niacina e minerais( ${ }^{(1)}$.

\section{Categoria 2. Mitos e tabus}

Inexiste leite fraco
Cada mãe Que o seu produz
Ter pouco leite ou arrotar
Em nada disso produz
Paz e calma para mãe
É mentira Que introduz
Foram mitos Que inventaram
Pode sim acreditar
Não existe um sabor igual
Cada leite é para dar
Adequado para o filho
Que saudável vai ficar

Consoante encontrado em estudos realizados sob a temática amamentação e com enfoQue no desmame precoce, entre os fatores Que contribuem para tal fato, estão leite "fraco", ou "o peito secou" ou a criança "largou" o peito. Estas afirmações são improcedentes e, desse modo, enfatizam a necessidade de campanhas informativas sobre o assunto ${ }^{(12)}$.

Há muitas dúvidas em relação ao aleitamento. Discussões sobre "leite fraco", "peito caído", "mama pequena" são indagações constantes no cotidiano de várias mães. É, pois, fundamental esclarecê-las, sobretudo se constituem um fator do desmame precoce, ou mesmo da não amamentação( ${ }^{(6)}$.

Quanto à eficácia do leite, não existe leite fraco e sua característica muda conforme a fase da amamentação. Nos primeiros dias de aleitamento, o leite é muito concentrado, grosso, transparente e com odor forte. É, também, muito nutritivo, e possui uma Quantidade elevada de anticorpos; é o denominado colostro, Que constitui a primeira vacina do bebê. Com alguns dias de mama, o leite muda de aparência de acordo com a duração da mamada. Nos primeiros minutos, o leite é de cor transparente, "branco aguado", e no final é amarelado e gorduroso ${ }^{(13)}$.

Como mencionam os versos, a intranqüilidade é um fator desfavorável, sobretudo no período de amamentação. Para evitar a inibição da secreção de ocitocina e, portanto, da ejeção de leite, é importante Que as mães tenham o puerpério tranQüilo, pois fatores psicogênicos ou, até mesmo, o estímulo generalizado do sistema nervoso simpático pode causar tal efeito(9). Para isso, é indispensável a atuação do enfermeiro na família, com vistas a facilitar o entendimento, o conhecimento e estimular a atenção à puérpera.

Um dos principais eixos norteadores da enfermagem é a educação em saúde e se concretiza nos vários espaços de realização das práticas em geral, sejam elas desenvolvidas em comunidades, serviços de saúde vinculados à atenção básica, escolas, creches, famílias e outros locais. Isso resulta pensar a ação educativa como eixo fundamental para a formação profissional do enfermeiro no referente ao cuidado de enfermagem e à necessidade de identificar ambientes pedagógicos capazes de potencializar essa prática ${ }^{(14)}$.

\section{Categoria 3. Profissional, família e amamentação}




\author{
E qualquer dúvida pode \\ Profissional indagar \\ Na saúde sempre ajudam \\ Nisso pode acreditar \\ Enfermeiros têm prazer \\ Para educar, ensinar \\ Assim a intranqüilidade \\ Que a mãe tem pode gerar \\ Não existe amamentação \\ E isso pode atrapalhar \\ Por isso felicidade \\ Amor e paz vamos dar \\ Quando a família tiver \\ Dúvida no amamentar \\ De como a criança pega \\ Não é necessário estressar \\ Pois a função da família \\ É sempre a paz aumentar

Sempre em todos os momentos
Lembra-se do pai também
Para ajudar a mãe Que
Lá na tristeza detém
Lágrima, intranqüilidade
Isto muito não convém

Quando se aborda a proximidade de mãe e filho, salienta-se Que o aleitamento aumenta o contato físico, proporcionando uma possível desenvoltura da criança no relacionamento com outras pessoas. Entretanto, a mamadeira é um objeto muito utilizado pelos pais para alimentar a criança. Segundo relatado por pesQuisadores, há uma tendência da criança, Quando ocorre o uso da mamadeira, a ficar se alimentando sozinha (principalmente as crianças maiores), assim como há falta de contato corpo a corpo com a mãe e probabilidade da criança se engasgar ${ }^{(13)}$.

Como se sabe, crianças em aleitamento materno exclusivo têm menos chances de desenvolver Quadros infecciosos, porquanto o leite materno é isento de bactérias e contém fatores antiinfecciosos, como: leucócitos, células brancas Que matam bactérias; anticorpos; imunoglobulinas Que protegem os bebês contra diversas infecções; macrófagos, células Que produzem interferon, substância Que protege contra infecções virais; fator bífido, substância Que facilita o crescimento de uma bactéria denominada Lactobacillus bífidus no intestino da criança, impedindo o crescimento de outros tipos de bactérias causadoras de diarréia; e lactoferrina, substância Que associada ao ferro previne o crescimento de bactérias patogênicas, as Quais precisam deste nutriente para a sobrevida; e lisozima, enzima Que atua na destruição ativa de bactérias ${ }^{(13,15)}$. Nos bebês, $\mathrm{o}$ ato de sugar o peito da mãe ajuda no desenvolvimento das mandíbulas. Isto pode diminuir o risco de má-oclusão, pois há o exercício favorecido por este músculo. Em crianças alimentadas por mamadeira, são freqüentes as dificuldades na fala e com a língua, pois o leite é fornecido de um bico artificial ${ }^{(13)}$.

De modo geral, todas as mães devem ser orientadas a amamentarem somente seus filhos. Essa medida visa prevenir suas crianças de serem contaminadas por possíveis patógenos Que podem ser encontrados no leite materno, caso sejam amamentadas por outras mães ${ }^{(10)}$. Mas as mães com excesso de leite podem doá-lo ao banco de leite. Nele o primordial é a doação e ressalta-se a arte de doar e o amor à vida.

De acordo com a literatura, doenças diarréicas, desnutrição, anemia e infecções respiratórias são fatores Que provocaram mais de um milhão de mortes no mundo em 1990. Desnutrição e doenças decorrentes da má nutrição causam mortes de 40 mil crianças a cada dia nos países em desenvolvimento ${ }^{(16)}$. Com a doação do leite, muitos bebês são beneficiados, e supre-se, nestes casos, a necessidade de amamentação do bebê Quando a mãe não pode satisfazê-lo. A exemplo de outros serviços, os Bancos de Leite Humano também oferecem orientações a gestantes, puérperas e familiares sobre dúvidas relacionadas à amamentação. Desse modo, tentam resgatar e incentivar a prática do aleitamento materno ${ }^{(17)}$.

\section{Categoria 4. Vantagens da amamentação para a criança}

\author{
Até seis meses de idade \\ Diz nossa Organização \\ A Mundial de Saúde \\ Sempre entende desta ação \\ É preciso oferecer \\ O líQuido na nação
}

\begin{abstract}
Também no leite materno Muitas vantagens existem Para mãe, filho e planeta E para todos persistem Neste enorme conteúdo Que para todos exigem
\end{abstract}

Não recomenda-se bico Mamadeira oferecer Isto causa confusão À mãe Que sempre Quer ver A saúde do seu filho E saudável pra crescer

Além destes nutrientes Que foram esclarecidos Quando ele sugar o peito Foi também favorecido Dificuldade na fala Com a língua não tem sido

Usar mamadeira aumenta Alguns riscos já citados Obesidade é um deles Mas não muito Questionado Alergia e cárie também Serão muito comentados

Aleitamento materno Outra substância tem 
Endorfina é nomeada

E Que a muito se detém

Vai diminuir a dor

Que nas crianças convém

As mães não podem nem deve

A outras crianças doar

Este seu leite materno

Sempre bom orientar

Pois a contaminação

Os bebês podem pegar

E com a aproximação

Existe apego também

Faz proteger a visão

Porque a vitamina A tem

No leite pode encontrar

Vantagens Que se detêm

Isso nós sempre chamamos

Amamentação cruzada

Não permite acontecer

Pois seremos atrasada

Mulher Que não for esperta

Vai ser é coisa passada

O leite sempre terá a

Temperatura ideal

Não é necessário temer

Pois não é um meio virtual

Se ele está frio ou vai Queimar,

Se vai gastar um real

A criança Quando mama

A mãe sempre sentirá

O seu filho perto dela

Isso sempre ajudará

A tranQüilizar a mãe

Nesse mundo Que virá

Sobre a doação do leite

Isto é importante lembrar

Existem alguns bebês

Que não conseguem mamar

Ou por motivo da mãe

Necessário ressaltar

É preciso incentivar

Às mães para a doação

É uma maneira de ajudar

E isso chama-se de união

Várias crianças supridas

Por esse leite em Questão

Afora as inúmeras vantagens proporcionadas pela amamentação, ela favorece maior rapidez na redução do volume uterino, evitando hemorragias no pós-parto. Ocorre também a estimulação de contrações, diminuindo o tamanho do útero e expulsando a placenta pela produção do hormônio denominado ocitocina. As contrações agem nos vasos sanguíneos da mulher, reduzindo o sangramento. Este ciclo de involução uterina é de fundamental importância, pois a hemorragia pós-parto é considerada uma das principais causas de mortalidade materna no Brasil ${ }^{(13)}$.

Inegavelmente, a amamentação traz muitas conseqüências positivas para a mulher e seu filho. Além de aumentar o apego e a interação do binômio e diminuir o risco de uma possível hemorragia pós-parto, a mulher que amamenta tem menos chance de contrair câncer de mama. Segundo algumas pesQuisas e estudos realizados, houve demonstrações de redução do risco de desenvolvimento do câncer de mama em até 30\%. Ainda como observado, o aleitamento, independentemente do número de filhos amamentados e da idade materna na primeira e na última amamentação, diminui o risco deste tipo de câncer ${ }^{(18)}$.

Embora a amamentação reduza a chance da mulher ter câncer de mama, não se pode afirmar Que garanta a prevenção deste tipo de câncer, pois já foram registrados casos de mulheres Que amamentaram por um tempo bastante significativo e mesmo assim foram vítimas dessa doença. Os fatores Que levam a isso são inúmeros, mas cada vez há maior evidência de Que a amamentação oferece proteção adicional à mulher.

Outras vantagens do aleitamento podem ser mencionadas, tais como: o aleitamento exclusivo diminui o risco de anemia, porque não há perda de sangue mensalmente durante a menstruação, ou seja, o "estoque" de ferro não é reduzido e conseQüentemente não há deficiência de ferro no organismo ${ }^{(13)}$.

Logo, o aleitamento materno é a maneira mais econômica para a família em termos de alimentação do bebê. Cada mãe tem o leite ideal e adequado para seu filho. Além dessas vantagens, outras existentes favorecem toda a família, pois a criança Que mama apresenta menos problemas de saúde, portanto, adoecer menos e os pais e família terão menos preocupações ${ }^{(13)}$.

A amamentação é também um ato ecológico. A cada mulher Que não amamentasse existiriam economias relevantes de alumínios e papéis para os rótulos de leite infantil. A maior parte desses produtos são poluidores tanto em sua produção e distribuição, como em seu empacotamento, promoção e exposição(13).

\section{Categoria 5. Vantagens da amamentação para a mãe e família}
Sabão, álcool, outro QualQuer
Produto usar na limpeza
Isso não deve fazer
Pode assim causar tristeza
Pois se secar o mamilo
Não se verá mais beleza
Quem amamentar seu filho
Não irá mais gastar dinheiro
Com mamadeira e nem leite
Durante este mês inteiro
Nem também remédio e gás
De janeiro até janeiro

Também existe influência 
Para a mamãe Que amamenta Evita a hemorragia Pois então expulsa a placenta Esta onde o seu bebê cresce E Que pra muitos não atenta

Ressalta em alguns estudos Que a mamãe não amamentar O risco de adQuirir câncer Pode assim até aumentar De ovário e endométrio Não é preciso constatar

Diminui então o sangramento Que possa vir a existir E assim o câncer de mama Menor risco a contrair Protege contra a anemia E isso assim não há por vir

Se a mamãe, papai e família Souber economizar Papéis, alumínio e vidro Precisa valorizar Também plástico e borracha E silicone não usar

Protege contra a anemia PorQue sua menstruação Demorará mais um tempo Para então entrar em ação E isso só vai acontecer Só com a amamentação

E todos esses produtos Vão causar poluição Os recursos naturais São usados na produção Também o fazem na sua Grande distribuição

Comunicar significa pôr em comum, colocar o mesmo assunto em Questão entre duas ou mais pessoas. Quando o mesmo assunto é entendido da mesma maneira, pode-se dizer que o diálogo e a comunicação estão sendo realizados. Há uma comunicação funcional na Qual todos estão entendendo da mesma maneira o assunto abordado naQuele momento.

Por comunicação funcional entende-se a capacidade de transmitir e receber mensagens, com base no contexto ambiental. Essa comunicação deve ser transmitida de modo efetivo e independente ${ }^{(19)}$.

Ao se transmitir uma comunicação, existe uma finalidade. A finalidade da comunicação em saúde é contribuir para o êxito desse processo, no caso, a amamentação. Vários são os fatores passíveis de influenciar no êxito do aleitamento materno. Alguns destes estão relacionados à mãe, como: características de sua personalidade $\mathrm{e}$ atitude diante da amamentação, além de outros referentes à criança e ao ambiente, como as condições em Que o bebê nasceu, o período pós-parto e fatores circunstanciais, a exemplo do trabalho materno e das condições habituais de vidaa ${ }^{(13)}$.

Como parte do processo de educação, é importante que o profissional de saúde responsável por essa gestante tente trabalhar observando e identificando Quais destes fatores mais influenciam na situação de amamentar. Com base nesse conhecimento, ele pode interferir e orientar essa mãe para manter a amamentação.

A comunicação é o meio ideal para trabalhar esta gestante. Quando o enfermeiro se disponibiliza a ajudar e identificar algum fator Que impeça a amamentação, caso esse exista, ao conversar e interagir na mesma linguagem da mãe e intervir positivamente, este diálogo será entendido pela puérpera e gerará bons resultados, como também melhor Qualidade deste processo ${ }^{(6)}$.

\section{Categoria 6. Comunicação em saúde}
A comunicação é vista
Como meio interessante
De educação na saúde
E também significante
No Que diz amamentar
Pois é assunto interessante
Tenho Que finalizar
Essas palavras falando
É importante amamentar
Mas também vou ressaltando
Que entender cada contexto
Isso é importante ir lembrando
Amamentar é um ato bem
Prático e também perfeito
Assim não gastar dinheiro
E a criança ser sujeito
É só levantar a blusa
Pois o bebê tem direito

\section{CONSIDERAÇÕES FINAIS}

A construção desta tecnologia é um meio de educação em saúde fundamental para mães e pais, afinal a amamentação não é um ato apenas materno, mas envolve toda a família. Desse modo, saber como agir com a puérpera ajudará na traneüilidade desta, e, assim, as condições referentes à problemática do desmame precoce poderão ser mais bem reajustadas.

Atualmente a literatura de cordel é considerada um meio de comunicação de massa bastante difundido e utilizado no Nordeste do Brasil. Ela possui uma Quantidade significativa de informações que podem ser usadas a QualQuer momento por QualQuer pessoa de modo geral. Sua inserção na área de saúde precisa ser efetivada e difundida, pois certamente contribuirá para a promoção da saúde da população. Ademais, os cegos precisam ser mais informados e orientados, porque este público, por não possuir visão, tem menos oportunidades de ser orientado, já Que as orientações, muitas vezes, são repassadas em folhetos e panfletos distribuídos de forma inacessível às pessoas com deficiência visual.

Nesse contexto, o enfermeiro é um ator fundamental, pois é o 
profissional Que explicará e incentivará a família a participar deste processo. Com a tecnologia assistiva (cordel cantarolado) para os cegos, o profissional sentirá mais segurança em disseminar o conteúdo e perceber Que está contribuindo para o conhecimento.
Conforme se acredita, a inovação na criação de um cordel específico sobre amamentação escrito por enfermeiros poderá estimular a utilização desta ferramenta para a divulgação técnico-científica e, ao mesmo tempo, se constituirá num poderoso recurso educacional.

\section{REFERÊNCIAS}

I. Rocha PK, Prado MD, Wal ML, Carraro TE. Cuidado e tecnologia: aproximações através do modelo de cuidado. Rev Bras Enferm 2008; 61 (1):1 13-5.

2. Merhy EE. Em busca de ferramentas analisadoras das tecnologias em saúde: a informação e o dia a dia de um serviço, interrogando e gerindo trabalho em saúde. In: Merhy EE, Onoko R, organizadores. Agir em Saúde: um desafio para o público. $2^{\text {a }}$ ed. São Paulo: Hucitec; 2002. p.1 13 - 50.

3. Cezário KG, Pagliuca LMF. Tecnologia assistiva em saúde para cegos: enfoque na prevenção de drogas. Esc Anna Nery Rev Enferm 2007; I I (4):677-8 I .

4. Bersch R. Introdução à tecnologia assistiva [on line] 2005 [citado 2008 jul 8]. Disponível em: http://www.cedionline.com.br/ artigo_ta.html

5. Lima AV. Acorda cordel na sala de aula. Fortaleza (CE): Tupynameuim; 2006.

6. Oliveira PMP. Literatura de cordel como meio de promoção para o aleitamento materno [monografia]. Fortaleza (CE): Faculdade de Farmácia, Odontologia e Enfermagem, Universidade Federal do Ceará; 2007.

7. Pagliuca LMF, Oliveira PMP, Rebouças CBA, Galvão MTG. Literatura de cordel: veículo de comunicação e educação em saúde. Texto Contexto Enferm 2007; I6(4):662-70.

8. Ministério da Saúde (BR). Política de aleitamento materno. [on line] 2007 [citado 2007 out 20]. Disponível em: http:// portal.saude.gov.br/portal/saude/cidadao/visualizar_ texto.cfm?idtxt $=26350$

9. Hall JE, Guyton AC. Tratado de Fisiologia médica. $10^{\mathrm{a}}$ ed. Rio de Janeiro: Guanabara Koogan; 2002.
10. Giugliani ERI. Alojamento conjunto e amamentação. In: Freitas F, Martins-Costa SH, Ramos JGL, Magalhães JA. Rotinas em obstetrícia. $5^{\mathrm{a}}$ ed. Porto Alegre: Artmed; 2006.

11. Leveno KI, Cunningham FG, Gant NF, Alexander JM, Bloom SL, Casey BM et al. Manual de obstetrícia de Williams. $2 \mathrm{I}^{\mathrm{a}} \mathrm{ed}$ Porto Alegre: Artmed; 2005.

12. Escobar AMU, Ogawa AR, Hiratsuka M, Kawashita MY, Teruya PY, Grisi S, et al. Aleitamento materno e condições socioeconômico-culturais: fatores Que levam ao desmame precoce. Rev Bras Saúde Matern Infant 2002; 2(3): 253-61.

13. Giugliani ERJ. O aleitamento materno na prática clínica. I Pediatr2000; 76(supl 3): S238-S52.

14. Acioli S. A prática educativa como expressão do cuidado em Saúde Pública. Rev Bras Enferm 2008; 6I(1): 117-21.

15. Cabral E, Figueiredo JEF, Azevedo MF. Enfermagem no cuidado materno e neonatal. Rio de Janeiro: Guanabara Koogan, 2005.

16. Val-Rafael E. O significado da amamentação na percepção da mulher primípara [dissertação]. Fortaleza (CE): Faculdade de Farmácia, Odontologia e Enfermagem, Universidade Federal do Ceará; 2003.

17. Machado MMT. A conquista da amamentação: o olhar da mulher [dissertação]. Fortaleza (CE): Faculdade de Medicina, Universidade Federal do Ceará; 1999.

18. Romieu I, Hernandez-Avila M, Lazcano E, Lopez R, Romerolaime R. Breast cancer and lactation history in mexican women. Am I Epidemiol 2007; 143 (6).

19. Garcia FHA, Mansur LL. Habilidades funcionais de comunicação: idoso saudável. Acta Fisiatr 2006; 13(2):87-9. 